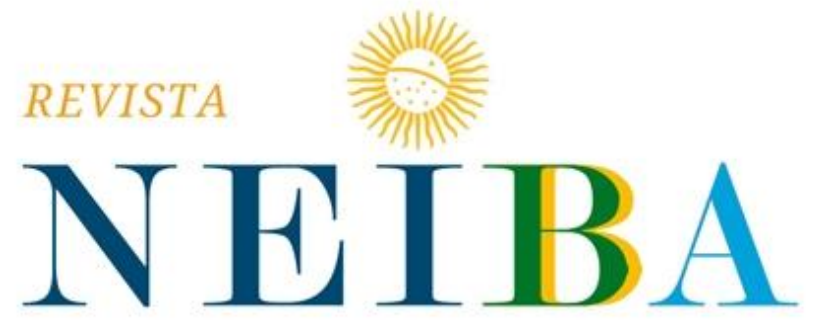

CADERNOS ARGENTINA-BRASIL
Volume 9, 2020, p. 01-17

DOI: $10.12957 /$ neiba.2020.50554 | e50554 I ISSN: 2317-3459

\title{
PÊNDULO DA POLÍTICA EXTERNA COMUNICACIONAL DO GOVERNO LULA: A EXPANSÃO DA TV BRASIL VIS-À-VIS A ADESÃO A TELESUR ${ }^{1}$
}

\section{PENDULUM OF LULA GOVERNMENT'S COMMUNICATIONAL FOREIGN POLICY: THE EXPANSION OF TV BRASIL VIS-À-VIS THE ADHESION TO TELESUR}

\section{Lucas Almeida de Brito ${ }^{2}$}

${ }^{2}$ Universidade de Estado do Rio de Janeiro (UERJ), Rio de Janeiro, RJ, Brasil. E-mail: lbrito.lucas@gmail.com ORCID: https://orcid.org/0000-0002-7881-5467

Recebido em: 01/01/2020 | Aceito em: 27/04/2020.

\footnotetext{
${ }^{1}$ Realizado com apoio da Fundação de Amparo à Pesquisa do Estado do Rio de Janeiro (Faperj).
} 


\section{RESUMO}

O presente trabalho tem como objetos de estudo a informação, o domínio do Estado sobre ela e a forma pela qual a informação se insere na política externa por meio das agências de notícias. Dessa forma, serão tratados aqui dois projetos de política de comunicação distintos sob a perspectiva da política externa: a Televisión del Sur (TeleSUR), que teve início de suas operações em 2005; e o projeto de expansão da TV Brasil criado no governo do presidente Luiz Inácio Lula da Silva, começando a operar em 2007. A hipótese é de que as escolhas tomadas quanto à contribuição a essas agências de notícias refletem um contexto maior de posicionamento da política externa brasileira, oscilando ora entre liderança e ora pela integração. A pesquisa foi conduzida através da busca de textos analíticos a respeito das duas instituições de notícias, além de informações coletadas nos meios eletrônicos institucionais, legislações e discursos. Palavras-chave: Política externa comunicacional; TeleSUR; TV Brasil.

\section{ABSTRACT}

The present work has as its study objects the information, the State's domain over it, as well as the way in which the information is inserted in the foreign policy through the news agencies. Thus, two distinct communication foreign policy projects will be addressed here: Televisión del Sur (TeleSUR), which started operations in 2005; and the TV Brasil's expansion project created under President Luiz Inácio Lula da Silva, starting to operate in 2007. The hypothesis is that the choices made regarding the contribution to these news agencies reflect a greater context for the positioning of Brazilian foreign policy, oscillating between leadership and integration. The research was conducted through analytical texts about the two news institutions, in addition to information collected in institutional electronic media, legislation, and speeches.

Keywords: Informational foreign policy; TeleSUR; TV Brasil. 
INTRODUÇÃO

Em 1527 o filósofo inglês Francis Bacon em sua obra Meditationes Sacrae fez uma de suas reflexões mais famosas quando escreveu que "informação é poder" (1985). Baseado nessa reflexão, o objeto do presente trabalho perpassa pela informação e o domínio do Estado sobre ela, bem como pretende entender como ela se insere em sua política externa. Dessa forma, serão tratados aqui dois projetos de política de comunicação distintos sob a perspectiva da política externa, a Televisión del Sur (TeleSUR), que teve início de suas operações em 2005 (TeleSUR, 2015) e o projeto de expansão da TV Brasil criada no governo do presidente Luiz Inácio Lula da Silva, começando a operar em 2007 (Bezerra, 2009).

A intenção aqui não é discorrer os pormenores dos dois projetos e sim analisar o intuito de expansão da TV Brasil em contraste ao projeto integracionista da TeleSUR a qual o Brasil não compactuou. Entendendo essa política de comunicações do governo Lula em questões alinhadas a política externa do governo.

A pesquisa realizada foi conduzida através da busca de textos analíticos a respeito das duas instituições de notícias, além de informações coletadas nos meios eletrônicos institucionais, legislações e discursos que tinham relação com o lançamento dos projetos, valendo ressaltar a pouca produção acadêmica da política de comunicações sob a ótica das Relações Internacionais (Matos, 2017).

O texto é dividido em três seções, além desta introdução. A primeira seção cuida do referencial teórico para análise posterior dos dois casos, que se deram em tempos não por coincidência contemporâneos, de iniciativas de comunicação para o continente. Esse referencial teórico se baseia na categoria muito utilizada por Nye (2004) de soft power que diz respeito a recursos não tangíveis do Estado para a propagação de sua influência, ou mesmo como uma defesa a influência externa, como é acentuado particularmente pelas interpretações do caso da TELESUR. Ainda na parte teórica o artigo de Letícia Pinheiro (2000) "Traídos pelo Desejo" é mobilizado com vista a embasar a interpretação da não aderência do Brasil a TeleSUR, diferente do que seus vizinhos fizeram e o projeto de expansão da TV Brasil que oscila entre uma postura grotiana ou hobbesiana de sua política externa. 
Na seção seguinte, será realizada uma breve retrospectiva, devido a iniciativa ser em um tempo recente, a respeito da criação da TeleSUR e da TV Brasil e o contexto e arcabouço jurídico sob o qual foram erguidas. Os dois projetos serão analisados de forma mais profunda, trazendo discursos e análises a respeito do posicionamento do governo Lula quanto a política de comunicação e de questões de conjuntura, mas também estruturais, que condicionaram o projeto político de criação e expansão da TV estatal. Sobre a TeleSUR será utilizado o conceito de diplomacia midiática de Eytan Gilboa (2011) e o contexto da discussão do projeto integracionista da Aliança Bolivariana para os Povos da Nossa América (ALBA). Com isso se busca elucidar a posição brasileira de não alinhamento direto e esclarecer os tímidos resultados conseguidos até aqui, bem como da ameaça de extinção de todo o projeto pelo vigente governo brasileiro de Jair Messias Bolsonaro.

Por fim, com a conclusão se busca um breve panorama do que aqui foi exposto e de apresentar o atual cenário da TeleSUR e da TV Brasil, bem como da Empresa Brasil de Comunicação (EBC) na qual está inserida.

\section{O PÊNDULO REGIONAL E INTERNACIONAL E O PAPEL DO PODER BRANDO}

O poder brando, ou soft power, nos termos de Joseph Nye (2004) cunhado no final dos anos 80 diz respeito a capacidade de dado Estado em influenciar, atrair ou convencer indiretamente o comportamento de outro Estado sem que tenha que empregar meios militares ou quaisquer outros de recursos tangíveis diretos. A influência corre por meios indiretos através de ferramentas culturais, diplomáticas e ideológicas, como uma forma de cumprir objetivos sem empregar uma violência (Nye, 2004, p.5).

Cabe mobilizar junto com o conceito de poder brando de Nye o de diplomacia midiática de Gilboa (2001), visto que no caso da TeleSUR se congrega os dois. A tecnologia tira a diplomacia apenas do âmbito formal da diplomacia estatal e do poder executivo. Agora há membros da sociedade civil e sobretudo da imprensa colocando novos desafios e práticas ao sistema internacional. Com isso temos três modelos analíticos da diplomacia midiática propostas por Gilboa. Esses três modelos variam 
dependendo de quais características e condições estão presentes caso a caso para a compreensão de qual deve ser empregado, são eles (Gilboa, 2001):

\section{Diplomacia pública}

Se trata da construção da imagem de um país no exterior, através de comunicações diretas com outros Estados, usando de intercâmbios culturais, científicos e artísticos ou através da mídia de massa. O objetivo final é influenciar o Estado alvo e/ou seus cidadãos. Ou seja, a maneira como indivíduos do governo ou entes privados influenciam as atitudes e opiniões públicas de outros Estados.

\section{Diplomacia na mídia}

A principal diferença em relação ao modelo anterior é que o elemento da propaganda é mais presente. Geralmente a diplomacia pública vem antes da diplomacia na mídia. A diplomacia na mídia se dá como uma espécie de método de negociação. Para Gilboa, no caso da diplomacia pública se pressupõe um confronto entre os Estados e ocorre uma preocupação com a imagem. Já nesse modelo os meios de comunicação fazem a ponte entre os Estados e atores não estatais, através dessa prática há a mobilização da opinião pública para esses acordos com vista a avançar nas negociações

e construir confiança. É feita através de coberturas, entrevistas e conferências. Esse contexto ainda que apresente o benefício de uma resposta eficiente, também mina o controle do Estado de todas as etapas do processo. Uma resposta pronta pode ocasionar uma avaliação equivocada da situação. Por outro lado, se não respondem prontamente passam a impressão que perderam o controle da situação.

\section{Diplomacia feita pela mídia (media-broker diplomacy)}

Esse modelo coloca a mídia na posição de ator no sistema internacional, a estrutura midiática seria o quarto poder, com seu peso nas organizações internacionais. No anterior, a mídia é um método e os atores que a compõe atuam da forma mais tradicional, cobrindo os fatos sendo a política conduzida pelos atores clássicos. Nesse modelo analítico, os jornalistas podem desempenhar função diplomática, podendo alterar os objetivos da política externa. Os jornalistas desempenham função de mediadores no período pré-negociação. 
Nos termos de Pinheiro (2000), a política externa brasileira adota estratégias e meios que podem ser orientado por um caráter realista hobbesiano - bebendo de fontes das teorias das Relações Internacionais e do filósofo inglês Thomas Hobbes (1588 - 1679) - preconcebendo um estado de anarquia no sistema internacional, isto é, a ausência de uma autoridade central levando com isso a um estado em que cada ator internacional se preocupa com sua própria segurança. Por outro lado, também pode abordar uma posição realista grotiana - oriunda teoricamente das ideias do jurista neerlandês Hugo Grotius (1583 - 1645), onde essa anarquia é regulada por normas internacionais. Ao longo da história da política externa brasileira houve um predomínio do realismo, respaldado pela constante busca pela autonomia na diplomacia brasileira. Autonomia definida em termos gerais como a busca de um país por uma margem de manobra em suas relações com outros Estados (Saraiva, 2013).

Vejamos agora esses conceitos à luz dos casos do projeto da TeleSUR e da TV Brasil, ambas tendo o recorte do governo Lula para análise.

\section{O LADO GROTIANO DO PÊNDULO: O CASO DA TELESUR}

A TeleSUR começou suas operações em 2005 e teve suas origens em um projeto idealizado por Hugo Chávez, presidente venezuelano de então, de criação de um veículo multi-estatal dos países latino-americanos que produzissem suas próprias notícias e tivessem seu próprio aparato e pessoal para esse fim (Calderón, 2005). Ela possui sede em Caracas com aporte pessoal, técnico e capital dos Estados que a compõe. O fluxo de informação até então se dava de uma forma que para se informar sobre as notícias de um país vizinho as principais empresas de mídias tradicionais do país compravam das grandes agências internacionais de notícias, que faziam uma espécie de pasteurização e enviavam de volta para o sul. Até mesmo as grandes empresas de imprensa do continente possuem escassos correspondentes pelo globo, fato que justificaria ainda mais a criação da TeleSUR (Moraes, 2017).

A TeleSUR contou no conselho consultor com diversos nomes latino-americanos, como o Nobel da paz, Adolfo Pérez Esquivel, o poeta Ernesto Cardenal, o escritor Eduardo Galeano e Ignacio Ramonet. Até agora, na breve história da TeleSUR, vale destacar alguns momentos: em 2007 a TeleSUR começa a transmitir para Cuba e se 
amplia em pessoal e rede de colaboradores; em 2008, fez a cobertura presente do ataque ao acampamento das Forças Armadas Revolucionárias da Colômbia (FARC); em 2009 ganhou proeminência internacional ao fazer uma cobertura internacional única do golpe de Estado ao presidente hondurenho Manuel Zelaya, ano em que também ingressou nas redes sociais e aprimorou suas páginas na internet; em 2010 faz uma cobertura da liberação de reféns pelas FARC, além disso se incorpora ao satélite Hotbird e com isso se expande para 123 países da Europa, Oriente Médio e África; em 2011 faz uma cobertura alternativa ao conflito na Líbia que veiculava algo que ia contra ao que era corrente entre os canais tradicionais que difundiam informações de uma capital toda destruída; em 2014 passa a produzir conteúdo em inglês (TeleSUR, 2015).

Em termos do relacionamento entre os Estados, essa mídia pode ser usada como um instrumento ou essa relação pode ser subvertida, tanto para as definições das pautas prioritárias de política doméstica quanto externa. Quanto a esse último aspecto, as pautas do Estado podem ser condicionadas pela mídia através da influência de uma agência internacional de notícias mais consolidada. Em termos práticos os Estados com baixas capacidades econômicas não conseguem desenvolver boas agências de notícias e acabam sendo afetados pela influência externa (Aguiar, 2015).

Como apontado por Valente (2014), ao menos 90\% das notícias internacionais veiculadas no Brasil por todos os jornais bebem da mesma fonte, isto é, as quatro principais agências internacionais de notícias, a Reuters (de natureza privada britânica com conglomerado que merge capital estadunidense e canadense com atual sede em Nova York), a EFE (de natureza estatal espanhola), a AFP (agência estatal francesa) e a AP (agência estatal estadunidense). Valendo citar que as duas que operam nos Estados Unidos são responsáveis por mais de 50\% das notícias internacionais veiculadas nacionalmente. Em termos de TV, dois dos principais canais de alcance global são estadunidenses: a Fox News e a CNN. Consumir de uma fonte externa as notícias que rondam o país tem grande impacto na agenda setting (conceito relacionado a hierarquia das pautas de ação), tanto dos jornais quanto do governo, por não possuir uma fonte própria eficiente de notícias. As pautas montadas nos jornais podem muito bem sofrer influência dessas quatro grandes agências. A hierarquização das pautas vem 
de informações já ranqueadas anteriormente por pelo menos três empresas estatais que as vendem para serem veiculadas por todo o país. É de grande interesse estratégico a manutenção dessas companhias estatais pelos seus Estados de origem, como importância geopolítica para afastar influências estrangeiras.

A TeleSUR vinha com o intuito de quebrar o monopólio e propor um projeto contra hegemônico para a região. Além disso, pode se inserir no conceito geral de autonomia apresentado, devido a ser uma busca por margem de manobra no contexto comunicacional. O projeto tinha o objetivo no papel de integrar os povos da América Latina e criar um eixo Sul-Sul que produzisse uma comunicação independente, projeto este impulsionado pelo Estado venezuelano com aderência de demais países da América do Sul, não por acaso a inauguração de suas transmissões se deu no dia de aniversário de Simon Bolívar, 24 de julho (Calderón, 2005). Houve a integração ao projeto dos governos de Cuba, Equador, Bolívia, Nicarágua, Uruguai e Argentina, com 16\% das ações (Suppo, 2017). Sobre a parceria Argentina e Venezuela cabe destacar, como aponta Monge, Vivas e Brizuela (2017), o presidente Néstor Kirchner em encontro com o presidente Chávez em fevereiro de 2005, assinaram acordos de cooperação na área das comunicações com o comprometimento argentino de aportar $20 \%$ das ações e oferecer apoio de pessoal e técnico. Porém o aporte nunca chegou a tal número. Com a eleição do candidato liberal Maurício Macri em 2015 a Argentina deixa oficialmente de ser uma sócia da rede (Ribeiro; Nogueira, 2017). Como efeito, em 2016, a TeleSUR já foi tirada da grade da principal empresa de televisão a cabo da Argentina, a Cablevisión, no lugar entrou a TVE, espanhola (Aznarez, 2016).

Vale citar ainda que a TeleSUR aparece como fruto de uma semente plantada nos anos 70 na proposta dos países não alinhados chamada, Nova Ordem Mundial da Informação e Comunicação. Em 1978, a Organização das Nações Unidas para a Educação, a Ciência e a Cultura (UNESCO) inspirada no projeto dos países não alinhados, lança os princípios que deveriam reger na época as mídias dos países então chamados de "Terceiro Mundo", conhecidos como os "quatros D's", (i) democratização; (ii) descolonização; (iii) desmonopolização e (iv) desenvolvimento (Suppo, 2017). 
O projeto da TeleSUR pode ser enquadrado como um projeto contra hegemônico e de poder brando, nos termos de Nye (2004). Se faz de um desafio e alternativa aos veículos predominantes de difusão de notícias na região. Apesar de já ter uma penetração em países de fora do continente, a TeleSUR se volta sobretudo para a América Latina e tenta romper com a tradição de se comprar notícias dos países vizinhos do Norte para depois serem veiculadas nas principais empresas nacionais de notícias.

Quanto a não adesão do Brasil, nos termos de Pinheiro (2000), cabe a interpretação do movimento da política externa brasileira que ao não aderir ao projeto da TeleSUR integralmente pode ser considerado como um movimento realista hobbesiano, que olhou para um projeto integracionista do qual não era líder como algo que pudesse afrontar seu desejo de liderança da região. O projeto não foi percebido como benéfico para o país que tinha seus próprios planos quando a política de comunicação. O Brasil se viu de frente com um projeto da TeleSUR que poderia ser enquadrado no realismo grotiano ao propor o recurso ao poder brando e apelar para uma cooperação no âmbito multi-estatal e recorrendo às normas construídas em conjunto para a fundação da instituição midiática. Vale mencionar, que a TeleSUR não pode ser considerada truculenta em sua afrontação aos meios tradicionais. Ela se propõe desde o princípio sobretudo a difundir entre os próprios países latinoamericanos suas notícias e pode ser enquadrada, nos termos apresentados em Gilboa (2001), como uma diplomacia midiática do governo Chávez, ao menos em seu princípio. Esse objetivo do canal pode ser encontrado no seu lema que é muito repetido nos intervalos de sua programação: "TeleSUR: conectando o Sul Global".

Vejamos agora a breve iniciativa brasileira durante o governo Lula de projetar a TV Brasil internacionalmente e compreender a sua não adesão a TeleSUR.

\section{A EXPANSÃO DA TV BRASIL: O OUTRO LADO DO PÊNDULO}

A TV Brasil começa suas atividades em dezembro de 2007 e vem a partir das fusões das TVs educativas dos estados do Rio de Janeiro, Maranhão e da TV Nacional de Brasília (Bezerra, 2009). Surge também a partir da criação da Empresa Brasileira de Comunicação (EBC) sob o decreto presidencial 6.246 que destina a ela um orçamento 
de vinte milhões para "suporte de operação dos serviços de radiodifusão pública" (República Federativa Do Brasil, 2007).

Vale citar como contexto para a criação da EBC e da TV Brasil, o I Fórum Nacional de TVs públicas, presentes representantes das emissoras públicas, educativas, culturais, universitárias, legislativas e comunitárias, onde teve como principal resultado a chamada "Carta de Brasília" na qual havia a recomendação de criação de uma TV pública de caráter nacional com base nos artigos 220, 221 e 223 da Constituição Federal. No texto (República Federativa Do Brasil, 1988):

Art. 220. A manifestação do pensamento, a criação, a expressão e a informação, sob qualquer forma, processo ou veículo não sofrerão qualquer restrição, observado o disposto nesta Constituição.

Art. 221. A produção e a programação das emissoras de rádio e televisão atenderão aos seguintes princípios:

I - preferência a finalidades educativas, artísticas, culturais e informativas;

II - promoção da cultura nacional e regional e estímulo à produção independente que objetive sua divulgação;

III - regionalização da produção cultural, artística e jornalística, conforme percentuais estabelecidos em lei;

IV - respeito aos valores éticos e sociais da pessoa e da família

Art. 223. Compete ao Poder Executivo outorgar e renovar concessão, permissão e autorização para o serviço de radiodifusão sonora e de sons e imagens, observado o princípio da complementaridade dos sistemas privado, público e estatal.

Segundo Suppo (2017, p. 20) o Brasil acaba por não participar da TeleSUR para recair o foco sobre a TV Brasil com uma alternativa "à mídia monopolizada". A EBC também é gestora da Agência Brasil, Radioagência Nacional e do sistema público de Rádio. Além disso, a EBC também teve seu papel idealizado na "Carta de Brasília".

Antes do lançamento oficial, em 2005, foram realizados os primeiros testes para uma possível TV Brasil com escopo internacional. A primeira transmissão foi da cobertura do V Fórum Social Mundial ocorrido em Porto Alegre. O sinal foi difundido para diversos países das Américas e da Europa Ocidental, tendo sido toda realizada em espanhol. Foi assim, que em setembro daquele mesmo ano foi inaugurada a primeira iniciativa de TV pública internacional brasileira, a TV Brasil - Canal Integración (o que viria a ser futuramente remodelada para a TV Brasil Internacional). A primeira transmissão oficial se deu com a cobertura da I Reunião de Chefes de Estado da 
Comunidade Sul-Americana de Nações (CASA). O objetivo era a integração dos países da América do Sul, através do intercâmbio do fluxo de informações. O lema do canal era "Diversidad, es nuestra identidad" ${ }^{3}$. A TV Brasil se inspirou em sua criação nos modelos administrativos adotados por outros países como no caso da BBC, na Inglaterra; a TVE, espanhola; a PBS, dos Estados Unidos; RTP, de Portugal, entre outras. Quanto ao conteúdo o canal passou a contar com editais públicos abertos para a produção desses materiais, anteriormente os programas das TVs educativas que haviam sido incorporadas eram veiculados na grade. Com a abertura de editais, em 2009 uma boa parte, 25\%, da programação foi renovada. A TV Brasil Internacional surge em 2010 em um projeto de três fases para a integração: (i) atender a América Latina; (ii) oferecer um serviço voltado para a África lusófona; (iii) atender as comunidades brasileiras no exterior (Bezerra, 2009).

Segundo Monge, Vivas e Brizuela (2017), a TV Brasil possui um acesso difícil, mesmo dentro de território nacional o único serviço de TV por assinatura que contava com ela em sua grade era a Vivo de São Paulo. Para os críticos do governo a TV Brasil foi uma espécie de aparelhamento do governo petista e que estagnou no tempo, se utilizando ainda do sinal VHF, considerado ultrapassado e que com isso afetando a qualidade das imagens que chegam pela transmissão (Suppo, 2017).

Com o discurso do lançamento da TV Brasil Internacional proferido pelo presidente Lula em maio de 2010 é possível notar um objetivo de produzir uma rede de TV visando a propagar a imagem do Brasil de forma, pelo menos no discurso, apolítica:

Pois bem, então, o que nós queremos provar, na verdade? Nós queremos provar que é possível fazer uma TV pública de qualidade, republicana, que não seja nem "chapa branca", mas que também não seja oposição a priori, que tenha discernimento de fazer a análise política correta, de contar os fatos como eles são, desagrade a quem desagradar ou agrade a quem agradar. Nós queremos uma TV pública que possa mostrar o Brasil lá fora, como ele é (República Federativa Do Brasil, 2010).

Ainda na fala de Lula:

Uma televisão que possa discutir política com clareza, que possa discutir economia com clareza, que possa dar uma outra visão de que o mundo não tem apenas a língua inglesa, de que o português só vai se respeitar quando ele for ouvido e quando ele for falado.

\footnotetext{
${ }^{3}$ Para ver a propaganda institucional acessar: $<$ https://www.youtube.com/watch?v=JwZm0OtVnj0>
} 
Não existe, ao menos no discurso, um aspecto de integração da TV Brasil Internacional ao resto da América Latina nem uma vontade de exercer liderança. 0 próprio projeto deixa claro esse aspecto ao não adotar por sua própria natureza, uma iniciativa multi-estatal. A TV Brasil é uma TV pública brasileira, tal qual era ansiada desde a promulgação da Constituição Federal de 1988, já a TeleSUR sempre se propôs a ser um órgão multi-estatal com integração capital e técnica dos países membros.

Vale trazer aqui a reflexão do jornalista Trajano de Moraes (2017) que caracteriza o Brasil como "gigante indeciso" diante desses dois projetos que se colocaram diante dele e o plano integracionista venezuelano como falho ao não conseguir a adesão brasileira. No entanto, para além do projeto autônomo brasileiro na área da comunicação, ocorrem projetos de uma certa forma concomitantes para a região, a Aliança Bolivariana para as América (ALBA) junto com o momento do Brasil como paymaster da região, que arcaria com os custos da integração por diversos meios na região (Saraiva, 2010). Ambos os projetos eram vistos como não hegemônicos como aponta Samuel Pinheiro Guimarães (2008), de integração entre as comunicações.

Porém, por serem semelhantes, tais projetos de uma certa forma competiam entre si e o fruto dessa concorrência no setor comunicacional foi o surgimento do projeto integracionista da TeleSUR em face a um outro projeto de liderança solo do Brasil em sua TV Brasil (Canal integración e depois internacional). Ambos possuíam o mesmo intuito contra hegemônico. Tendo a TeleSUR surgido, não por acaso, poucos anos antes do início oficial da TV Brasil, que já estava com testes sendo realizados no mesmo ano do lançamento da TeleSUR. Nesse ponto vemos o Brasil pender para o lado realista hobbesiano, ainda nos termos de Pinheiro (2000), ao não compactuar com o projeto venezuelano por não consentir um projeto integracionista no qual não fosse o líder. 0 Brasil reinterpretou a situação para buscar sua autonomia, agora em um outro nível, o da comunicação.

O projeto da TV Brasil Internacional esbarrou com um detalhe estrutural da política doméstica brasileira, o grande oligopólio familiar que divide a comunicação e que cresceu institucionalmente no seio do governo desde a ditadura militar. Segundo Bolaño e Brittos (2008), há uma "anomalia" devido a existência de emissoras públicas, 
mesmo as consideradas essenciais para a transparência como, a TV Senado, Câmara e Justiça, postas fora do lugar que normalmente se encontram nos países, ficando a um patamar pouco popular em relação às grandes empresas de mídia. Há pouco espaço visto a grande reserva que é feita da TV aberta para essas poucas empresas. Ainda segundo os autores, a máquina acaba sendo tão complexa e azeitada que mesmo os mais progressistas dos governos quando ascendem ao comando não conseguem desmontá-la pois, sobretudo, precisam delas para a sua própria manutenção no poder. A TV Brasil pouco tinha chance diante desse cenário. Parece que diante de tal quadro, a melhor chance para o Brasil teria sido a adesão, ou a liderança, de uma emissora multiestatal nos moldes da TeleSUR, porém o trem da história já tinha partido.

Vale por último ressaltar que o Brasil possui um traço quanto a sua política externa voltada para a América do Sul, por vezes financia e consolida órgãos já existentes de regionalismo aberto, como o Mercosul; e por outro lado também fomenta iniciativas de cooperação e integração de menor envergadura (Saraiva, 2010). Talvez uma outra hipótese é a de que o governo brasileiro havia considerado a TeleSUR como um apoio a uma iniciativa incipiente e menos estruturada, já que deu ajuda logística, na sua origem, e também de pessoal quando houve a inauguração da representação do canal em Brasília (Gonçalves; Júnior, 2006).

\section{CONCLUSÃO}

O presente trabalho pretendeu elucidar um ponto com pouca bibliografia produzida na área da política externa. Se preocupou em contrapor dois projetos comunicacionais que começaram contemporaneamente na região da América do Sul com objetivos muito similares, porém com grandes diferenças em suas estruturas. Um deles, a TeleSUR, nasceu como uma iniciativa multi-estatal liderada pela Venezuela com o intuito de se construir um órgão de notícias que produzisse e veiculasse notícias da América Latina e que fosse a principal alternativa para os outros meios internacionais tradicionais, que "pasteurizavam" a notícia antes que fossem veiculadas nos órgãos nacionais mais tradicionais.

No outro lado temos o projeto de expansão da TV Brasil que se originou durante o governo Lula. Projeto muito ousado, pode-se dizer, devido à natureza dos veículos de 
comunicação do Brasil, com um oligopólio tradicional e enraizado. A TV Brasil contou com orçamento e logística financiada pelo Estado brasileiro, era um projeto de TV pública e não multi-estatal, por isso também estava exposto aos condicionantes dessa questão estrutural que engessa as novas iniciativas no meio da comunicação ou mesmo as fadam ao fracasso. O projeto era de integração, principalmente em relação aos países lusófonos, aos brasileiros que residem no exterior e a propagação da imagem do país por meios governamentais.

As alternativas que foram apresentadas à inserção internacional no meio da comunicação foram contrapostas se utilizando do arcabouço teórico proposto por Pinheiro (2000) que analisa concomitantemente uma postura da política externa brasileira entre um realismo grotiano e um realismo hobbesiano. Aqui focando no projeto da TeleSUR de uma integração nos moldes de uma ação grotiana (no seu fortalecimento e criação de instituições entre os países da América Latina), e da expansão de um ideal de integração da TV Brasil moldado internamente, uma postura hobbesiana, de autoajuda e de liderança de certa forma imposta. Também é considerada como hobbesiana a postura de não adesão a TeleSUR pelo Brasil.

Como apontado anteriormente a TV Brasil, e a EBC como um todo, foram vistas pelos críticos ao governo como um aparelho petista e tem sido vítima de ameaças de extinção. Não se pode dizer realmente que a TV Brasil tenha sido bem-sucedida até o momento. A TV Brasil - Canal integración foi desmantelada e reformulada para a TV Brasil Internacional deixando um pouco de lado o projeto original integracionista que se via em suas propagandas institucionais. Além disso, o sítio da internet para a TV Brasil Internacional é instável e tem poucas informações institucionais para acesso ${ }^{4}$, com as últimas atualizações datando do ano passado, 2018. Ainda assim a reforma seria uma alternativa mais racional do que o desmantelamento de toda a EBC, como o atual presidente Jair Bolsonaro vem insinuando em seus discursos (Soares, 2019). A TV Brasil Internacional possui também um canal no YouTube, com 8,5 mil inscritos ${ }^{5}$.

A TeleSUR por sua vez possui um website bem estruturado onde é possível acessar todos os telejornais e programas gratuitamente e para assisti-los sob demanda, há

\footnotetext{
${ }^{4}$ Para acesso ver: $<$ http://www.ebc.com.br/tv-brasil-internacional $>$

${ }^{5}$ Para acesso ver: $\langle$ https://www.youtube.com/user/TVBRASILful $>$
} 
também a possibilidade de assistir a transmissão ao vivo pelo site e tudo isso em alta definição ${ }^{6}$. Ainda conta com uma assistência para que qualquer pessoa que queira relatar uma notícia possa fazê-lo. Todas as funcionalidades também estão disponíveis em um website em inglês que também é acessível através de dispositivos móveis ${ }^{7}$. Além disso, a TeleSUR conta com aplicativos para celular tanto para sistemas Android ou IOS. Possui um canal no YouTube, com transmissões ao vivo e vídeos dos programas disponíveis, até o momento da escrita deste artigo possuía 675 mil inscritos ${ }^{8}$, também possuem um outro em inglês, com $111 \mathrm{mil}^{9}$. Por último, a empresa ainda conta com presença nas principais redes sociais, valendo ressaltar que possui 1,7 milhões de seguidores no Twitter $^{10}$.

Mesmo com toda assimetria em relação a poderes mais tangíveis do Brasil em relação a seus vizinhos, a TeleSUR se fez um instrumento até aqui bem-sucedido, mesmo com a recente saída da Argentina da iniciativa, de poder brando e na sua origem de diplomacia midiática (Gilboa, 2001) do governo venezuelano. A TeleSUR é de fácil acesso, funciona 24 horas por dia e é e de amplo alcance que pode ser observada a partir das participações de diversos intelectuais e ativistas em seus programas. Já a TV Brasil parece à beira de sua extinção com a EBC, que infelizmente é relacionada a um determinado governo, do que algo que serve ao Brasil como todo. Até o presente momento o impacto foi muito tímido. O Brasil foi "traído pelo desejo", dessa vez sua autonomia comunicacional, abortada pelo seu próprio problema estrutural interno e pelo fato de ter se fechado a um projeto de um único país, acabou perdendo a chance de se criar um veículo de notícias próprio nos moldes da BBC, TVE, e entre outros modelos que tanto almejou.

\footnotetext{
${ }^{6}$ Para acesso ver: $<$ https://www.telesurtv.net/ >

${ }^{7}$ Para acesso ver: $<$ https://www.telesurenglish.net/ $>$

${ }^{8}$ Para acesso ver: $<$ https://www.youtube.com/user/telesurtv >

${ }^{9}$ Para acesso ver: < https://www.youtube.com/user/telesurenglish >

${ }^{10}$ Ver: $<$ https://twitter.com/telesurtv >
} 


\section{REFERÊNCIAS BIBLIOGRÁFICAS}

Aguiar, P. (2015). 'Agências de Notícias Brasileiras e Conglomerados de Mídia: concentração, convergência e dependência', Intercom - Sociedade Brasileira de Estudos Interdisciplinares da Comunicação.

Aznarez, C. (2016). A pesar de Macri y Cablevisión, seguiremos viendo teleSUR. Disponível em: <https://www.telesurtv.net/bloggers/A-pesar-de-Macri-y-Cablevisionseguiremos-viendo-TeleSUR-20160303-0002.html>. [Acesso em: 21 de jul. de 2019.]

Bacon, F. (1985). Meditationes sacrae. Londres: Excusum impensis Humfredi Hooper.

Bezerra, H. (2009). Verbete: TV Brasil. Disponível em: <http://www.fgv.br/Cpdoc/Acervo/dicionarios/verbete-tematico/tv-brasil>. [Acesso em: 21 de jul. de 2019.]

Bolaño, C. R. S.; Brittos, V. C. (2008). 'TV pública, políticas de comunicação e democratização: movimentos conjunturais e mudança estrutural', Revista Eptic, 10(3).

Calderón, C. A. (2005). '¿Qué és teleSUR?', Revista Chasqui, №. 92.

Gilboa, E. (2001). 'Diplomacy in the media age: Three models of uses and effects', Diplomacy and statecraft, 12(2), p. 1-28.

Guimarães, S. P. (2008). 'O mundo multipolar e a integração sul-americana', Temas \& Matizes, 7(14), p. 58-72.

Matos, C. (2017). 'Prefácio'. In: Suppo, H. (Comp.), TeleSUR: ¿poder blando contrahegemónico?.Rosario: Edición UNR-UERJ, p. 9-16.

Monge, D.; Vivas, C.; Brizuela, L. (2017). 'Diez años de TeleSUR: características y trayectoria'. In: Suppo, H. (Comp.), TelesUR:¿ poder blando contrahegemónico?. Rosario: Edición UNR-UERJ, p. 35-53.

Moraes, T. (2017). 'Brasil, o gigante indeciso'. In: Suppo, H. (Comp.), TeleSUR: ¿poder blando contrahegemónico?. Rosario: Edición UNR-UERJ, p. 156-169.

Nye, J. (2004). Soft power: The means to success in world politics. New York: Public affairs.

Pinheiro, L. (2000). 'Traídos pelo Desejo: um ensaio sobre a teoria e a prática da política externa brasileira contemporânea', Contexto Internacional, 22(2), Rio de Janeiro: IRI/PUC-Rio, p. 305-336.

República Federativa do Brasil. (1988). Constituição da república federativa do Brasil. Brasília: Senado Federal, Centro Gráfico.

(2007). Decreto no 6.246, de 24 de outubro de 2007. Cria a Empresa Brasil de Comunicação - EBC, aprova seu Estatuto e dá outras providências. Disponível em: 
<https://presrepublica.jusbrasil.com.br/legislacao/94411/decreto-6246-07>. [Acesso em: 21 de jul. de 2019].

(2010). Presidente (2003-2011: Luiz Inácio Lula da Silva). Discurso do Presidente da República, Luiz Inácio Lula da Silva, durante solenidade de lançamento da TV Brasil Internacional. Brasília, 24 de maio. Disponível em: <http://www.biblioteca.presidencia.gov.br/presidencia/ex-presidentes/luiz-inacio-lulada-silva/discursos/2o-mandato/2010/14-05-2010-discurso-do-presidente-da-republicaluiz-inacio-lula-da-silva-durante-solenidade-de-lancamento-da-tv-brasil-internacional>. [Acesso em: 20 de jul. de 2019.]

Ribeiro, A.; Nogueira, S. (2017). 'Entre símbolos e notícias: a construção da integraçãoregional pelo portal TeleSUR'. In: Suppo, H. (Comp.), TeleSUR:¿ poder blando contrahegemónico?. Rosario: Edición UNR-UERJ, p. 99-132.

Saraiva, M. G. (2010). 'Brazilian foreign policy towards South America during the Lula Administration: caught between South America and Mercosur', Revista Brasileira de Política Internacional, v. 53, p. 151-168.

(2013). 'Continuidade e mudança na política externa brasileira: As especificidades do comportamento externo brasileiro de 2003 a 2010', Relações Internacionais (R:I), n. 37, p. 63-78.

Soares, J. (2019). Promessa de campanha, EBC será extinta, afirma Bolsonaro. Disponível em: <https://oglobo.globo.com/brasil/promessa-de-campanha-ebc-seraextinta-afirma-bolsonaro-23708282>. [Acesso em: 22 de jul. de 2019.]

Suppo, H. (2017). 'Introdução'. In: Suppo, H. (Comp.), TeleSUR: ¿poder blando contrahegemónico?. Rosario: Edición UNR-UERJ. p. 17-34.

TeleSUR. (2015). Acerca de Telesur, Historia. Disponível em: $<$ https://www.telesurtv.net/pages/sobrenosotros.html>. [Acesso em: 22 de jul. de 2019.]

Valente, L. (2014). 'O controle estadunidense dos fluxos internacionais de informação e o domínio da cyberpolitik', O Debatedouro, 84(1). Disponível em: $<w w w . o d e b a t e d o u r o . f i l e s . w o r d p r e s s . c o m>$. [Acesso em: 20 de jul. de 2019.] 